\title{
BMJ Open Qualitative exploration of patient flow in a Caribbean emergency department
}

\author{
Loren De Freitas (D) , ${ }^{1}$ Steve Goodacre (1) , ${ }^{1}$ Rachel O'Hara, ${ }^{1}$ Praveen Thokala, ${ }^{1}$ \\ Seetharaman Hariharan ${ }^{2}$
}

To cite: De Freitas L, Goodacre S, 0'Hara R, et al. Qualitative exploration of patient flow in a Caribbean emergency department. BMJ Open 2020;10:e041422. doi:10.1136/ bmjopen-2020-041422

- Prepublication history and additional material for this paper is available online. To view these files, please visit the journal online (http://dx.doi.org/10. 1136/bmjopen-2020-041422).

Received 08 June 2020 Revised 04 November 2020 Accepted 12 November 2020

A) Check for updates

(c) Author(s) (or their employer(s)) 2020. Re-use permitted under CC BY-NC. No commercial re-use. See rights and permissions. Published by BMJ.

${ }^{1}$ School of Health and Related Research (ScHARR), University of Sheffield, Sheffield, UK ${ }^{2}$ Anaesthesia and Intensive Care Unit, University of the West Indies, Eric Williams Medical Science Complex, St. Augustine, Trinidad and Tobago

Correspondence to

Dr Loren De Freitas;

lorendefreitas@gmail.com

\section{ABSTRACT}

Objectives Emergency departments (EDs) are complex adaptive systems and improving patient flow requires understanding how ED processes work. This study aimed to explore the patient flow process in an ED in Trinidad and Tobago, identifying organisational factors influencing patient flow.

Methods Multiple qualitative methods, including nonparticipant observations, observational process mapping and informal conversational interviews were used to explore patient flow. The process maps were generated from the observational process mapping. Thematic analysis was used to analyse the data.

Setting The study was conducted at a major tertiary level ED in Trinidad and Tobago.

Participants Patient and staff journeys in the ED were directly observed.

Results Six broad categories were identified: (1) ED organisational work processes, (2) ED design and layout, (3) material resources, (4) nursing staff levels, roles, skill mix and use, (5) non-clinical ED staff and (6) external clinical and non-clinical departments. Within each category there were individual factors that appeared to either facilitate or hinder patient flow. Organisational processes such as streaming, front loading of investigations and the transfer process were pre-existing strategies in the ED while staff actions to compensate for limitations with flow were more intuitive. A conceptual framework of factors influencing ED patient flow is also presented.

Conclusion The knowledge gained may be used to strengthen the emergency care system in the local context. However, the study findings should be validated in other settings.

\section{INTRODUCTION}

Improving emergency department (ED) patient flow requires understanding the work processes that create flow problems. ${ }^{1}$ For this study, ED patient flow has been defined as the progressive movement of patients through care processes, where movement refers to the transformation of an input activity to an output, from arrival until the patient physically leaves the ED. ${ }^{23}$ Most previous studies addressing ED flow have been conducted in developed settings, focusing on effectiveness of interventions, but have not explored how and why the intervention was (un)able to produce its
Strengths and limitations of this study

Previous studies have been predominantly conducted in developed countries using quantitative methods.

- Strengthening emergency care systems is becoming a priority in developing countries but the Caribbean remains an under-represented region.

- This study explores emergency department patient flow in a developing Caribbean country using a multimethod qualitative design, primarily observational process mapping.

- Single observer used to collect data.

Singe site may produce context-specific findings.

effect, which is important for generalisability of findings. ${ }^{4}$

Implementing interventions without understanding and optimising factors that influence flow may worsen any inappropriate use of resources, increasing costs, leading to an unproductive system. ${ }^{5}$ This is particularly important in developing countries or developing emergency care systems where flow concerns are often compounded by limited resources and a lack of protocols to mitigate issues. In these settings, it is essential to develop robust, effective emergency systems as disease and migration patterns shift, burdening systems. ${ }^{6}$ WHO has placed strengthening emergency care systems on its agenda and consensus statements have noted that emergency care research in developing countries should include ED organisation and system design studies. ${ }^{6-8}$

Trinidad and Tobago is a developing country in the Caribbean with a developing emergency care system. The health system is a mix of public and private facilities. ${ }^{9}$ One previous study in Trinidad evaluated the usefulness of simulation modelling as a management tool to optimise an ED process. ${ }^{10}$ Although the study determined that simulation modelling was a useful tool to identify bottlenecks, a detailed analysis 
of factors influencing the patient flow process was not presented. ${ }^{10}$ Conducting research in developing settings, like the Caribbean, is essential to determine generalisability and transferability of knowledge on patient flow from developed settings as well as gaining new insights from developing settings.

Although there is a growing number of qualitative studies exploring ED patient flow, quantitative studies still dominate the current literature. ${ }^{4}{ }^{11}$ This study aimed to use qualitative observational methods to identify organisational factors influencing patient flow in an ED in Trinidad and Tobago.

\section{METHODS}

\section{Study design}

This study was part of a PhD project exploring patient flow in an ED. The project also explored what patients and staff considered valuable and wasteful in the patient flow process. In order to explore these areas, a pragmatic-critical realist approach was adopted using an exploratory case study design. ${ }^{12} 13$ The pragmatic approach focuses on the research problem and what method is best suited to understand the problem while critical realism attempts to uncover the underlying mechanisms that contribute to events and explain why things happen. ${ }^{14}$ Combining these approaches allow practical activities to construct reality. This approach allowed the researcher to generate data using multiple methods and using methods that were considered better suited to collect data in the emergency setting. Using the critical realist lens allowed the researcher to explore what was happening behind each step in the process.

Multiple qualitative methods were used including non-participant observations, observational process mapping and field conversations. These methods were not distinct, independent methods but rather the qualitative process was flexible and iterative with methods overlapping. Observational process mapping used direct observations to identify process steps such as activities, delays and decisions as well as what is happening to the patient. ${ }^{16}$ Maps reflected the patient process in its current form and were created as patients experienced the process and not on perception or assumptions. In process mapping, varying details of the steps in the process may be presented. A high-level map was defined as one that depicted only the main overall steps in the process. A medium-level map presented significant or sustained steps in the process while a low-level map presented minute details of each step in the process (eg, patient parks car, patient sits in waiting room). In this study, a combination of medium-level and low-level maps are presented. ${ }^{16}$

\section{Study setting}

The setting was an ED in a major public teaching hospital in Trinidad and Tobago, which had approximately 450

\begin{tabular}{ll}
\hline Table 1 Summary of ED areas \\
\hline ED area & Type of patient seen \\
\hline Level 1-3 ('critical area') & CTAS level 1, 2, 3 \\
Level 4 & CTAS level 4 \\
Minor operating theatre & $\begin{array}{l}\text { Minor trauma patients, } \\
\text { asthmatics }\end{array}$ \\
Level 5 ('triage') & CTAS level 5, triaging of patients
\end{tabular}

CTAS, Canadian Triage and Acuity Scale; ED, emergency department.

beds and an estimated $72000 \mathrm{ED}$ attendances annually. The ED used the Canadian Triage and Acuity Scale (CTAS).${ }^{17}$ ED areas reflected CTAS triage levels with a separate area for minor trauma patients, as summarised in table 1. Online supplemental file 1 presents the schematic layout of ED. Details of the workforce structure are also presented in online supplemental file 1.

\section{Data collection and processing}

Data were collected by the lead author, a PhD student familiar with the ED site. The research team consisted of an emergency physician, a qualitative researcher, an health economist and a local researcher. This collaborative approach served to limit the influence of any one researcher's background on the study. A pilot study was conducted in April 2017 to practice the process mapping technique and uncover any practical issues. Data were then collected from May to August 2017 with a follow-up session in November 2017.

Posters were displayed throughout the ED for the study period. These served to provide information on the study and inform the entire ED population that research was being conducted. When staff and patients were approached, verbal consent was obtained and participants were reminded that they did not have to participate. Purposeful sampling used variables such as staff experience, triage category and weekday to develop an in-depth understanding of the patient flow process exploring potential variation among triage categories, day of week and crowded periods. Observations were conducted on all 7 days of the week and lasted from 3 to 6 hours to limit researcher fatigue. In total, the data collection covered a 24-hour period in each of the main ED areas (06:00-12:00, 12:00-18:00, 18:00-00:00, 00:00-06:00 hours). Data collection continued until no new ideas, patterns and themes emerged. ${ }^{18}$ The observational data guide has been included as online supplemental file 2 .

In this study, the maps reflected the general organisational ED patient flow process rather than the process for a single patient or a clinical diagnosis / pathway. Steps taken by patients were recorded as they entered an ED area. In areas with high patient turnover (eg, triage), the number of ED patient journeys mapped was greater than in the other areas. If a patient was significantly delayed at a step ( $>1$ hour), the researcher then began 
observing another patient. Observations concluded when the patient's ED journey was complete or the observation time period ended. Observations focused on activity within the step as well activity around the patient with the aim of understanding how the process worked and why things occurred as they did.

During the study, the department was reconfigured, which was independent of the study. Details related to decision making and methods used to inform the reconfiguration were not accessible to the researchers. Since the reconfiguration provided an opportunity to observe and map the effects of the changes, the data collection period was extended to incorporate the changes. Detailed handwritten field and reflexive notes were recorded and transcribed into Microsoft Word 2016. Files were anonymised and labelled. Recording verbatim speech was difficult but 'speech in action' was included which described actions and speech used by participants as they occurred. ${ }^{19}$

Process maps were constructed in Edraw Max V.9.4 software. Review of maps occurred over four sessions from February to March 2018. Key staff members validated the maps, providing feedback, clarifying uncertain areas. Staff members included a consultant, head nurse, senior doctor and one representative each from the point-of-care testing lab, porter services and ED radiology department. Each session lasted approximately 1 hour. A scribe was present to record the data.

\section{Patient and public involvement}

No patients or members of the public were involved in the study design or conduct of this study.

\section{Data analysis}

Data were analysed with thematic analysis. ${ }^{20}$ NVIVO V.11 software facilitated the analysis. Analysis was an iterative process with preliminary analyses starting during fieldwork to allow for data saturation and continued into final analysis and interpretation phases. Codes and themes were inductively generated from the data but were influenced by descriptors developed in comprehensive literature reviews conducted prior to data collection. ${ }^{11}$ Thus, while the emphasis was on the generation of data-driven codes and themes, if there was a similar descriptor from the literature reviews, it was used. As qualitative research focuses on range and diversity of data, themes were based on relevance to the research question and not on number of occurrences in the data. ${ }^{21}$ A selection of transcripts and analytical themes were discussed with the coauthors who provided critical feedback.

\section{RESULTS}

A total of 203 hours of observations were conducted which included 48 hours of non-participant observations and 155 hours of observational process mapping with $143 \mathrm{ED}$ patient journeys mapped. Of these, 23 were categorised as CTAS level 1-3, 32 as level 4, 21 as minor operating theatre and 67 were registration/triage/ CTAS level 5 patients.

\section{Summary of process maps}

Four process maps were generated from the observational process mapping (figures 1-4). The main process map (figure 1) represents the ED patient flow process from entry to exit. On arrival to the ED, a triage nurse screened patients to determine if the ED was the appropriate place. Patients who were assigned to level 1 were taken directly to the resuscitation room for immediate management. All other patients registered and were formally triaged. Basic investigations were conducted at triage and patients assigned a CTAS level. ED clinicians assessed patients and investigations requested as needed. Patients were either discharged or referred to inpatient teams. Inpatient clinicians then assessed patients in the ED before making an admission decision.

Subprocess maps 1-3 represent key subprocesses related to the patient journey. Subprocess map 1 (figure 2) represents the process for basic investigations conducted at triage. Subprocess map 2 (figure 3) represents the process for diagnostic investigations conducted in the main ED, that is, after patients were assigned to triage categories. The last process map represents the transfer process (figure 4). This map presents the steps taken during the transfer of admitted patients from the ED to inpatient wards.

\section{ED reconfiguration}

Observations revealed that the reconfiguration was mainly a change in the physical layout of the ED rather than a significant re-arrangement of the steps in the patient flow process. Two main changes were observed: an existing patient examination room that housed non-ambulatory patients was converted to a dedicated examination room for ambulatory patients. The second change was the conversion of the level 4 area into a 'holding bay' (similar to a short stay unit) to temporarily accommodate patients who were either referred to inpatient teams or awaiting admission to the inpatient wards. Online supplemental file 3 summarises the changes in the reconfiguration.

\section{Overarching categories identified as organisational factors influencing the patient flow process}

Overall, the analysis generated six overarching categories that appeared to influence patient flow. Organisational processes such as streaming, front loading of investigations and the transfer process were pre-existing strategies in the ED while staff actions to compensate for limitations with flow were more intuitive. Within each category there were individual factors that appeared to either facilitate or hinder patient flow. These are presented in the following section with supporting evidence in table 2. 


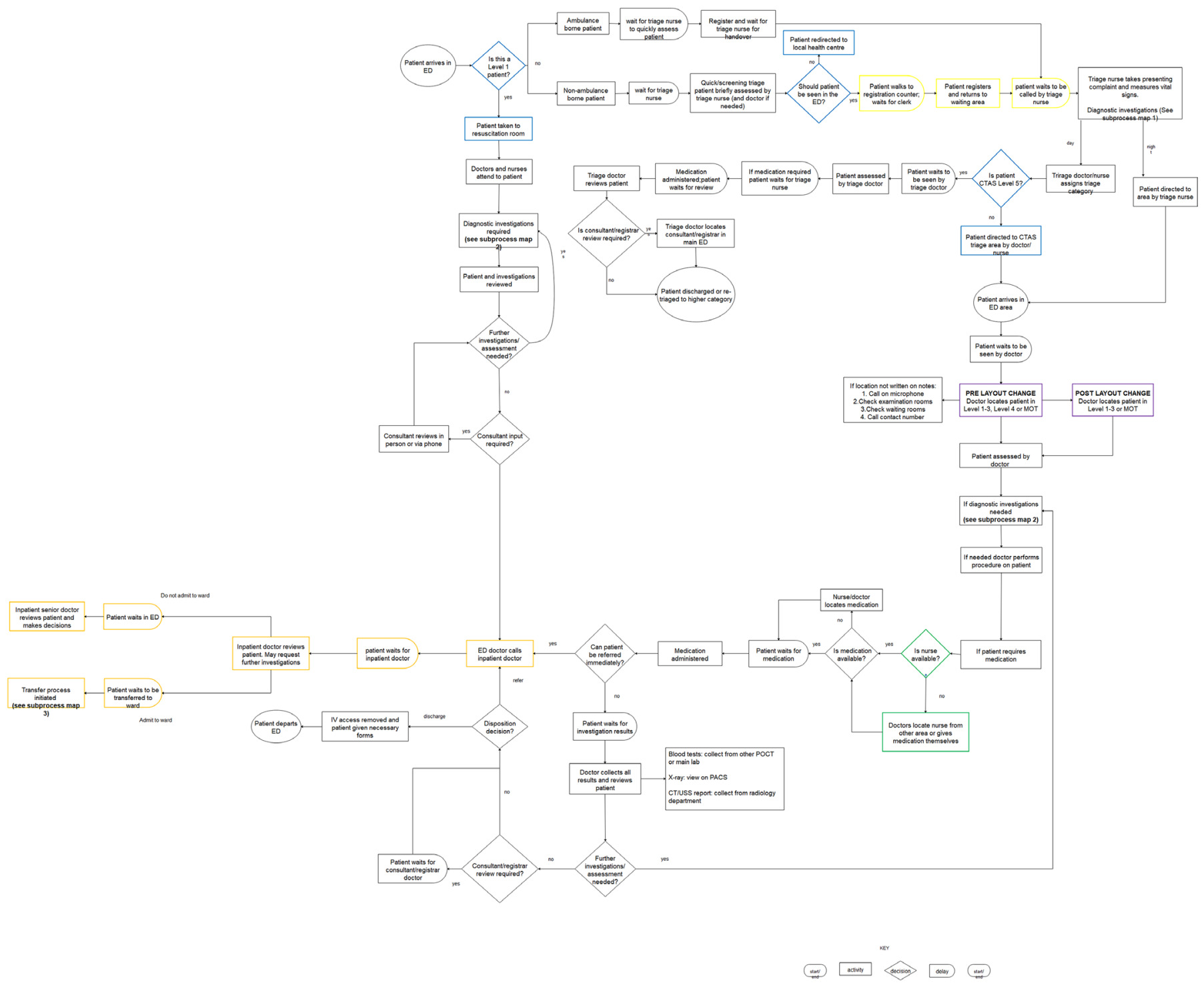

Figure 1 Main process map of patient flow. CTAS, Canadian triage and acuity scale; ED, emergency department; PCOT, pointof-care testing.

\section{ED organisational work processes}

The ED organisational work processes relevant to patient flow were identified as streaming of patients, front loading of investigations, flexible assessment options for ambulatory patients and the transfer process.

Streaming, allocation and re-distribution of staff facilitates simultaneous flow of multiple patient groups

The triage process was combined with streaming at the start of the patient journey. In the triage process, patients were first screened to determine if the ED was the appropriate place to receive care. If the decision was made that the ED was not the appropriate place, the patient was re-directed. If the ED was deemed the appropriate service, then patients registered and formally assessed. Patients were then allocated to streams with each stream representing a CTAS level and one for minor injuries. The combined streaming and triage process appeared to facilitate flow, prioritising seriously ill patients at the onset of the patient journey.
Each stream had its own dedicated space, staff and material resources allowing staff to simultaneously assess multiple patient groups. The process map in figure 1 highlights the decision and activity steps that reflect the streaming process (steps marked blue). The allocation of clinical staff to each stream also facilitated patient flow. Doctors (house officers) and nurses were assigned to each stream with greater numbers of clinical staff assigned to higher priority streams. Lastly, there was flexible redistribution of staff to match areas of demand. The combination of these factors appeared to promote good patient flow.

Front loading of investigations at triage reduced steps for patients The front loading of investigations intended to facilitate patient flow. Requesting basic investigations (ECGs, urine tests, X-rays for minor injuries) during the triage process appeared to improve flow by reducing the number of steps after the main clinical assessment. Figure 2 presents 

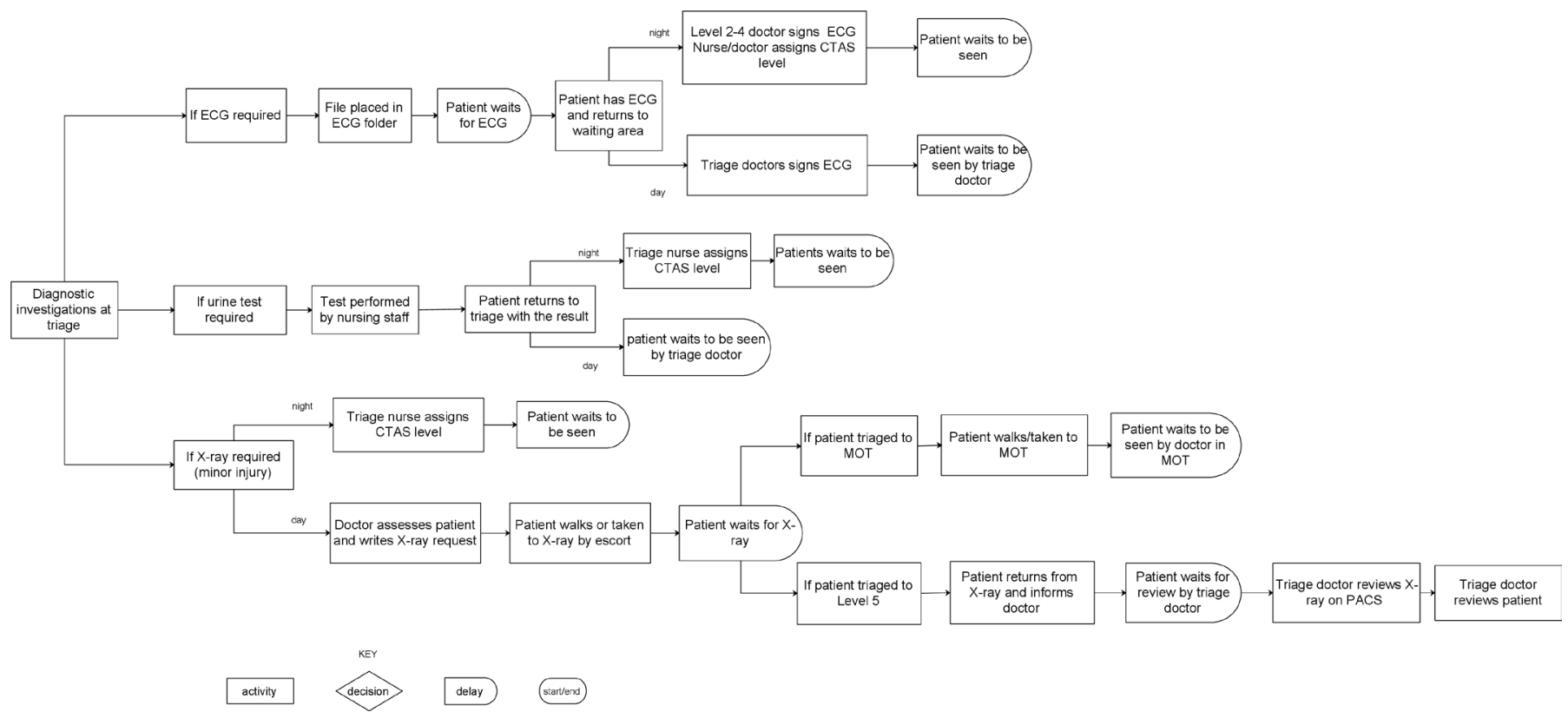

Figure 2 Subprocess map 1: diagnostic investigations at triage. CTAS, Canadian Triage and Acuity Scale.

the process map of the front loading of investigations during the triage process.

Flexible assessment options facilitated flow for ambulatory patients

Observations revealed that patients were not automatically placed on trolleys in order to be seen by doctors. Doctors identified reasons such as patients being well enough to sit, insufficient trolleys and the need to anticipate future patients who may require a trolley, illustrated in the following extracts.
No, everyone can't get a bed because there aren't enough and even if there were available beds we wouldn't put someone on a bed if they didn't really need it. You also have to anticipate that someone else may come in who really needs the bed. (Registrar \#8, non-participant observations)

Clinically well ambulatory patients were often seen on chairs. This strategy of using chairs to assess patients was not a formal policy in the ED but appeared to be an implicit strategy aimed at prioritising trolleys for patients most in need. As a result, staff often spent time

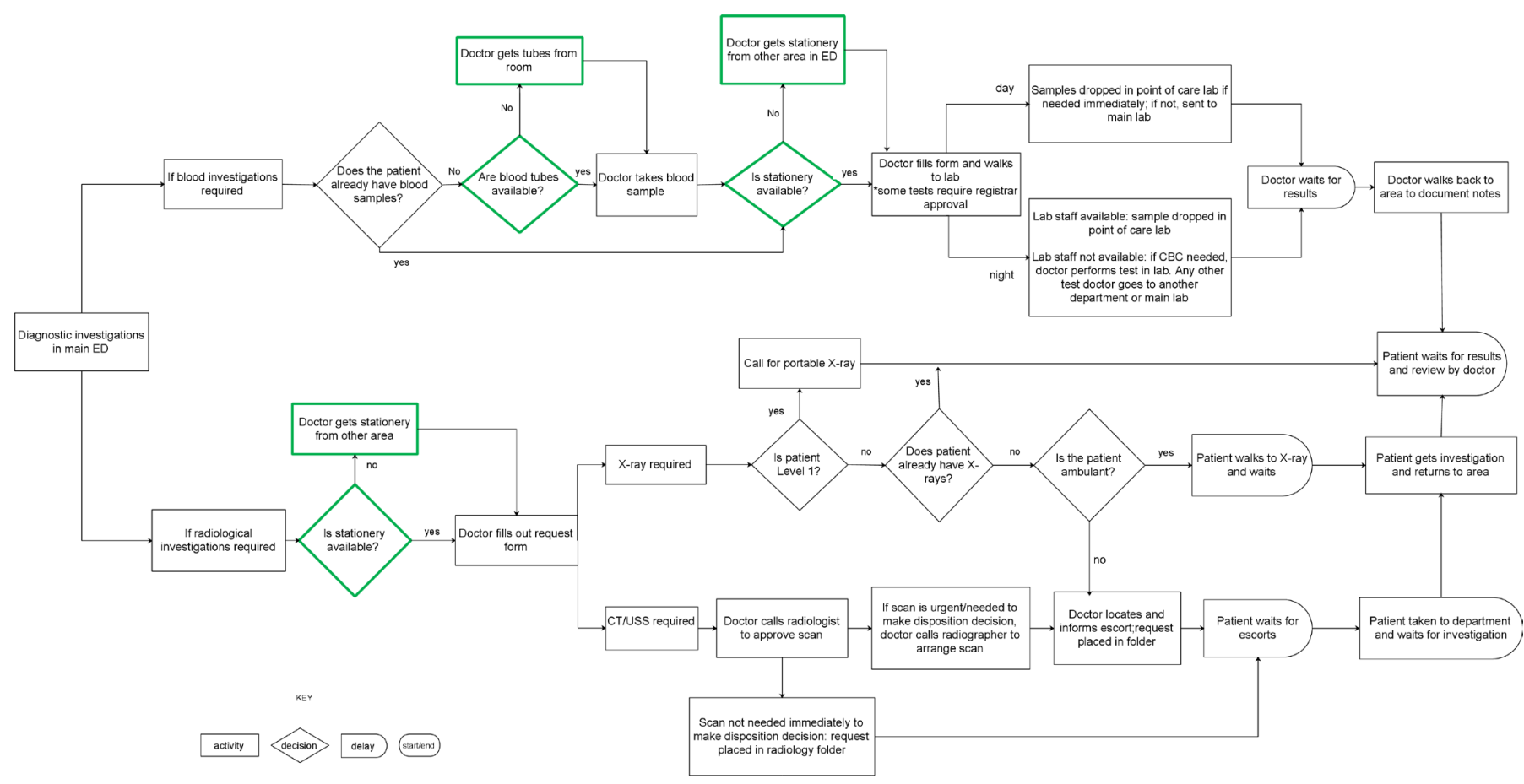

Figure 3 Subprocess map 2: diagnostic investigations in main emergency department (ED). 


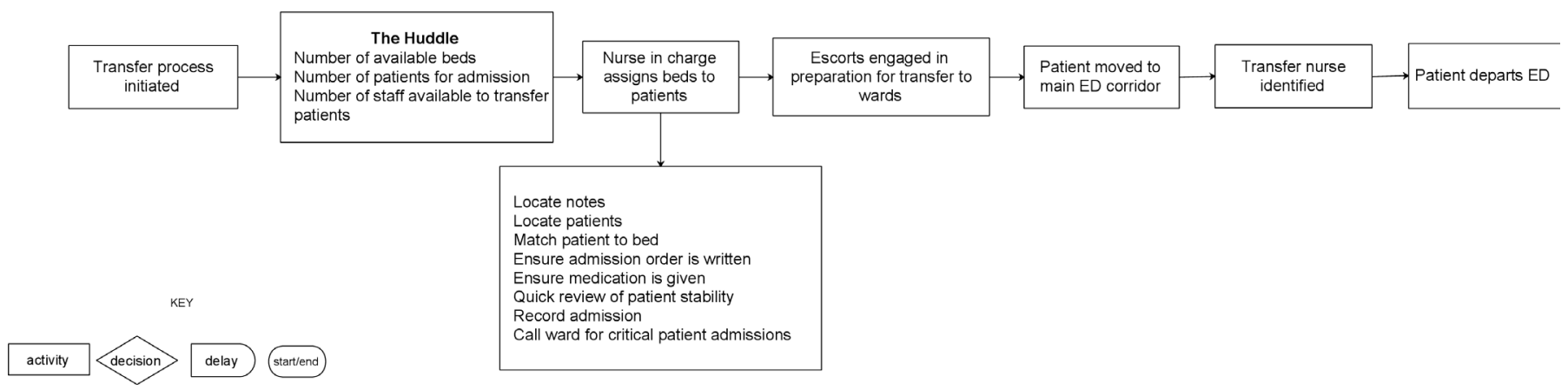

Figure 4 Subprocess map 3: transfer process. ED, emergency department.

searching for available space to use. Overall, the strategy itself appeared to facilitate patient flow since ambulatory patients did not have to wait for an available trolley to be seen and supported the appropriate utilisation of trolleys.

\section{Transfer process delays the outflow of admitted patients}

The transfer process referred to the movement of admitted patients from the ED to inpatient wards (figure 3). This was a complicated subprocess with multiple factors affecting each step with some factors facilitating outflow and others acting as barriers to good outflow. One aspect intending to facilitate patient outflow was a team meeting, ('the huddle'), that occurred at several intervals throughout the day. ED staff were regularly updated on the numbers of available inpatient beds, patients for admission and staff available to assist with patient transfers. This strategy was thought to provide 'structure and coordination' to the transfer process (consultant\#2).

Other observed factors appeared to act as barriers to the outflow of admitted patients. The activity of assigning admitted patients to inpatient beds comprised multiple steps, which appeared to consume staff time. Locating patient files was time consuming because of the involvement of external clinical staff who often did not return files to the nursing staff. Locating patients in the department was also a barrier because the patient location was not always documented on the files. Further delays in the process resulted from a lack of nurses and attendants required to transfer the patient.

\section{ED design and layout}

ED design and layout facilitated flow by supporting the organisational work processes

The ED layout appeared to support the streaming process by having distinct separate areas for each stream (see online supplemental file 1). The physical reconfiguration also highlighted the influence of design on patient flow. The introduction of an examination room specifically for ambulatory patients appeared to support the flexible assessment organisational work process and reduced time staff spent searching for available space.

Features of the ED layout created additional steps in the process Layout features that appeared to hinder flow included the physical separation of the registration and triage areas.
The separation of these areas created additional activity and waiting steps in the process which are reflected in the highlighted yellow steps in figure 1 .

In the physical reconfiguration, dedicated ED areas for referred or admitted patients (holding bays) were also introduced. This appeared to be useful for the overall organisation of the ED by separating admitted patients from those still receiving emergency care but overall, it appeared that the reconfiguration did not substantially alter the steps in the patient flow process. The process map (figure 1, highlighted purple steps) showed that the patients experienced the same steps but in a different area within the ED.

\section{Material resources}

Dedicated ED laboratory and radiology services facilitated patient flow

Dedicated ED point-of-care testing and X-ray services appeared to facilitate flow by providing results in a timely manner and reducing dependency on external departments.

Insufficient material resources in the ED led to increased motion searching for materials

Insufficient materials, such as phlebotomy and stationery materials, created unnecessary motion from staff searching for materials acting as a barrier to flow. The highlighted green steps in subprocess map 2 (figure 4) show how insufficient materials in the ED created additional steps in the process. Subsequent observations revealed that staff responded to the insufficiency by keeping specific materials on themselves to reduce time spent searching.

Lack of inpatient beds appeared to be a barrier to the outflow of admitted patients (transfer process)

Staff also noted the lack of available inpatient beds as a factor affecting outflow with one staff member stating, 'The biggest bottleneck in transferring patients out of the department is the lack of beds on the ward...' (Head nurse\#1). Further observations showed that this led to patients boarding in the ED which increased the workload for ED staff and exacerbated other factors influencing patient flow such as the shortage of nursing staff, described in the next theme. 


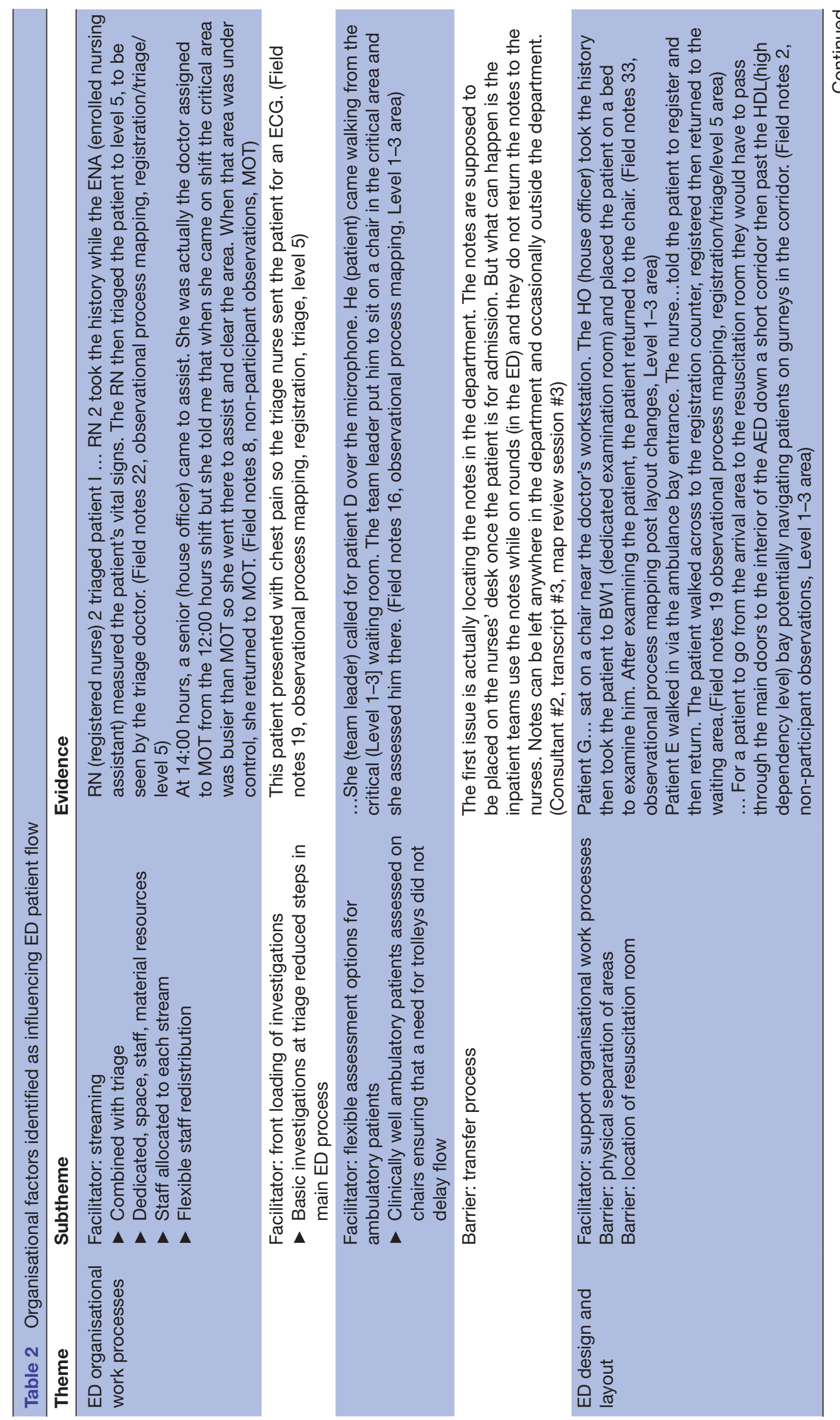




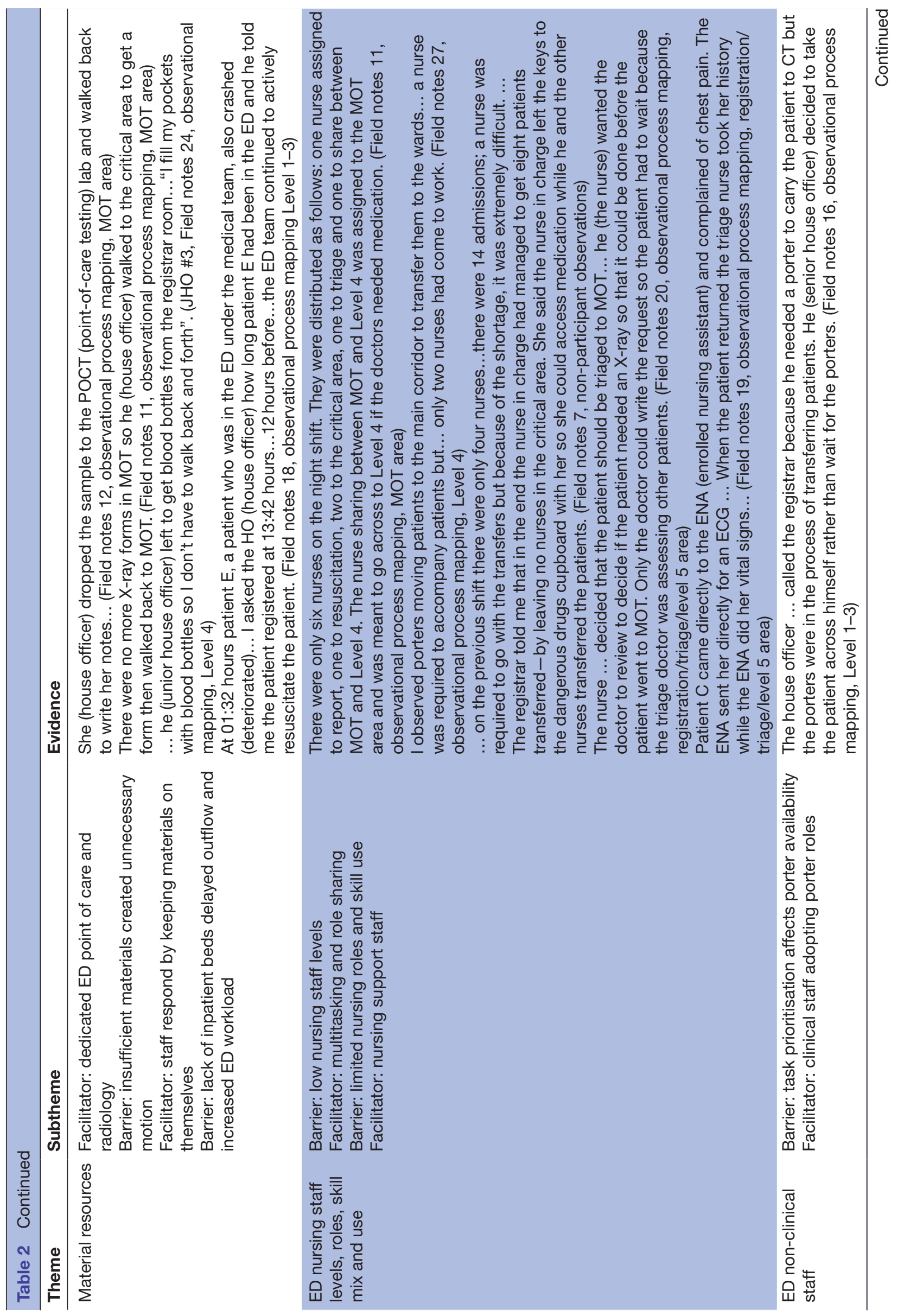




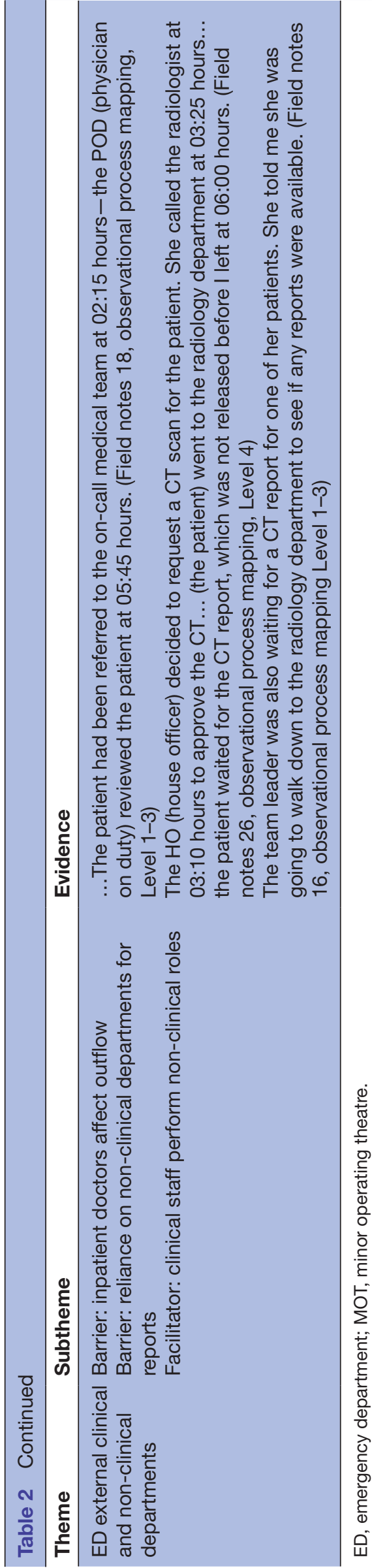

ED nursing staff levels, roles, skill mix and use

Nursing shortages compromised nurse-dependent steps leading to sharing of roles among staffing groups

Observations and field conversations revealed that each shift required 14 nurses but this number was not always met. The nursing shortage appeared to be most significant on night shifts, affecting the allocation of nurses to ED areas, leaving some areas unstaffed, which consequently acted as a barrier to effective streaming. The nursing shortage also led to delays in the triage process, administration of medication and the transfer of patients out of the ED. Highlighted green sections of figure 1 show how the nursing shortage delayed administration of medication and created extra steps in the patient process.

The nursing shortage resulted in nursing staff and doctors adjusting their roles to meet the demands of the department. Observations revealed that nurses multitasked, often assigned to manage multiple streams and doctors shared nursing roles to counter shortages. For example, in one instance a doctor shared nursing duties to allow the nurses to complete the transfer process.

Limited nursing roles and skill use created more doctor-dependent process steps

Observations revealed that nurses were unable to institute patient management, perform invasive clinical procedures or request investigations. Limited nursing roles appeared to influence the effectiveness of work processes, such as front loading of investigations, since only doctors could authorise requests for investigations. Registered nurses with additional training were not always able to use their skills because they mainly performed administrative roles. However, the nursing shortage affected nursing skill use, as one head nurse explained:

Even if nurses were allowed to do more, the current numbers wouldn't allow them to see patients because it would take away from the general nursing care required (Head nurse\#2)

Lastly, within the overall nursing staff category, there were a variety of auxiliary staff who supported registered nurses in their nursing duties, promoting flow.

\section{ED non-clinical staff}

Multiple duties of porters affected their availability acting as a barrier to patient flow

Patient progression often depended on availability of the porter staffing group. There was often conflict regarding which task (patient transfers to wards or transporting patients for investigations) should be prioritised. Although these duties facilitated flow for one group of patients, it hindered flow for the other group. Similar to the response to the nursing shortage, doctors carried out tasks that porters would normally be expected to undertake, in order to maintain flow. 


\section{External clinical staff and non-clinical departments}

Dependency on external departments delayed decision-making and patient outflow

Observations showed that external clinical staff, that is, non-ED doctors, appeared to influence flow, acting as a barrier to patient outflow. When patients were referred to inpatient doctors, these doctors assessed the patient in the ED before making their disposition decision. This often involved clinical assessment (history and examination) and requesting of further investigations. ED staff considered the rate at which the inpatient doctors assessed patients a major obstacle to patient flow.

This is the biggest delay in the department-waiting for the specialty teams to review the patient (SHO\#16).

As seen in figure 1 (highlighted orange steps), the inpatient team influenced the steps taken after an ED disposition decision was made.

Delays in receiving reports from non-clinical departments, such as the main hospital laboratory and radiology departments, appeared to influence flow not only because of longer waiting times but also because of a lack of a mechanism to alert doctors when results were ready. Again, doctors opted to perform non-clinical tasks, such as walking to departments to collect reports.

\section{Conceptual framework of factors influencing ED patient flow}

The findings from the literature review and the primary study were summarised in a conceptual model of factors influencing ED patient flow (figure 5). The model builds on the existing qualitative literature by providing further insight and explanation into how identified factors influenced patient flow. In the model, the findings were re-organised into six categories, based on a modified fishbone model. ${ }^{22}$ Within the categories, the model identifies specific factors that are considered either barriers or facilitators to patient flow. Although the model classifies the factors into broad categories, these factors do not exist in isolation. For example, while streaming and triage (methods) created simultaneous pathways and was considered a facilitator of patient flow, the method is dependent on having sufficient staff (staffing) to allocate to each stream (people). Thus, the model summarises the findings on the factors influencing ED flow and provides a structured approach to understanding patient flow.

\section{DISCUSSION}

This study used qualitative methods, primarily observational process mapping, to explore patient flow in an ED in a Caribbean island. The findings in the study are consistent with existing literature from both developed and developing countries. Factors common to other studies included a lack of inpatient beds and material resources, staff shortages and impact of inpatient teams. ${ }^{23-29}$ This current study had similar findings to one study conducted in Thailand, which identified staff shortages, high nurse workloads and inexperienced staff as factors affecting length of stay in the ED. ${ }^{30}$ Factors identified in other studies included conflicts between the ED physicians and other specialties, high nurse workloads, inexperienced staff and crowded EDs. ${ }^{30} 31$

In the primary study, clinically well ambulatory patients were assessed on chairs, facilitating flow for this patient group. This is similar to a 'fit to sit' strategy in the UK where suitable ambulance borne patients were placed on chairs on arrival to the ED. ${ }^{1}$ This finding is also supported by another qualitative study which promoted the use of

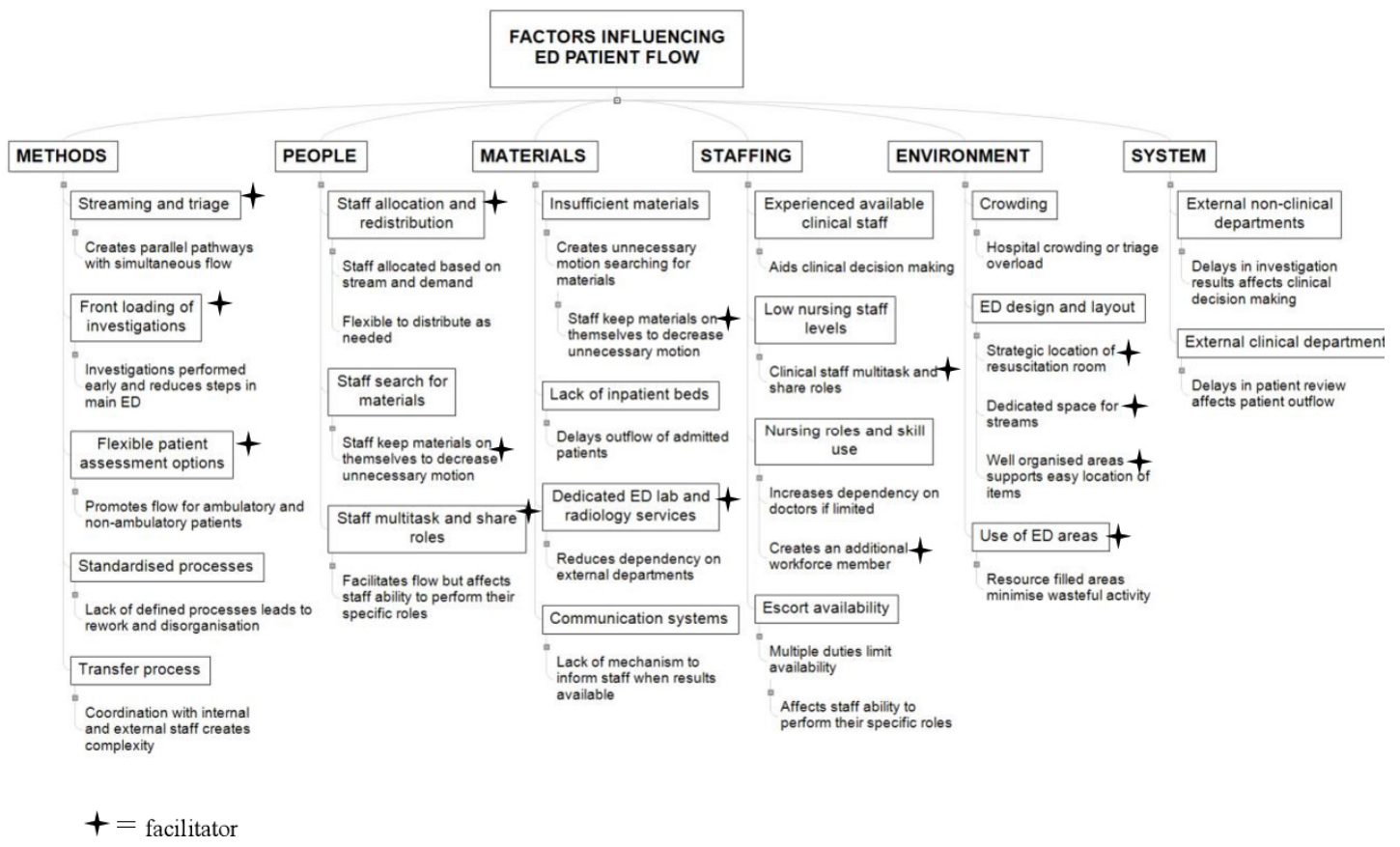

Figure 5 Conceptual model of factors influencing emergency department (ED) patient flow. 
chairs for ambulatory patients. ${ }^{32}$ However, it was noted that while the strategy aimed to improve waiting times, staff were often concerned about the lack of privacy and confidentiality associated with this open chair concept. ${ }^{32}$ Although not an area explored in the current study, it is possible that staff and patients in the study ED may express similar concerns. Additionally, in the current study, there were no formally documented departmental policies for any of the identified organisational work processes. For example, there were no criteria detailing which patients were appropriate for the use of chairs. These strategies may be generalisable to other settings (or may already exist in some form, as in the primary study) but standardisation of the intervention and formalising policies reduces guesswork and unnecessary activity, ultimately supporting good patient flow.

The ED reconfiguration undertaken in the primary study also highlighted the influence of design on patient flow. Participants in another study considered the ED layout as the most significant aspect of ED design. ${ }^{33}$ Design strategies should facilitate (effective) work processes while also considering how movement and activities of process users affect flow. ${ }^{34}$ Using this approach should aid decision makers when determining if restructuring the ED is a viable strategy to address flow concerns.

The nursing shortage and the limited use of nursing skills identified in the primary study was also a factor affecting flow in other EDs. ${ }^{24} 263035$ Nursing shortages are common in EDs regardless of the setting. ${ }^{36}$ However, nursing levels in developing countries are often further compromised because of migration from developing to developed countries. ${ }^{36}$ The UK Royal College of Nursing states that safe and effective staffing means 'having enough nursing staff with the right skills and knowledge, in the right place, at the right time'. ${ }^{37}$ Based on this, the ED case study had low safe nursing staff levels. Nursing roles, such as emergency nurse practitioners, are established in developed countries but are less common in developing countries. ${ }^{38}$ These are likely to be valuable in developing settings but require legislation, education and professional support for proper implementation. ${ }^{38}$

Staff actions such as multitasking and role sharing were often in response to increasing demands in the ED or perceived barriers to patient flow. This behaviour was noted in other studies with staff manipulating ED space by re-distributing patients to areas that were less busy or by staff persistently calling the external departments to remind them about the reports for investigations. ${ }^{27} 3539$ One study exploring interprofessional barriers related to ED patient flow had similar findings to this study. In that study, 'substituting down' was used to refer to doctors performing nursing tasks. ${ }^{31}$ However, while these actions may have facilitated flow, if they become sustained or permanent, it may affect the staff ability to perform their primary roles, which subsequently hinders patient flow.

\section{Strengths and limitations}

There are several limitations to this study. The data collection occurred in a single ED in Trinidad, which may not reflect the processes in all EDs in the country or other settings. Future research should focus on conducting larger studies across a wider range of settings to validate the findings. The fieldwork was also conducted by a single observer which may lead to researcher bias. However, several methods were used to minimise this risk. These included a prolonged length of time in the field, triangulation of data using multiple methods and data sources, sharing of transcripts with other authors and validation of process maps with key staff members.

Time constraints limited the number of hours of observations on admitted patients who remained in the $\mathrm{ED}$, which meant that this stage of the patient journey was not completely explored. The limited use of verbatim speech in the informal conversations may have affected the reliability of these data. Additionally, participants may have adjusted their behaviour in response to the observer's presence. However, the length of time in the field, the nature of the ED being an intense environment with staff who are likely to be constantly occupied and the high patient turnover may have reduced this effect. This study also did not explore areas such as organisational culture, professional relationships or power imbalances, which may provide additional insights into patient flow. Future studies, in addition to exploring the organisational patient flow process, may also benefit from incorporating how these areas influence patient flow and the organisational process.

In conclusion, this study contributes to knowledge on emergency care research in the Caribbean and may be relevant to other developing countries. The findings may be a step towards strengthening the ED in the local context, supporting the WHO emergency care systems objectives. The study findings also suggest that there are common flow concerns across settings; combining efforts has the potential to produce robust solutions. However, future research is needed to validate the study findings using larger studies across a wider range of settings.

Acknowledgements The authors would like to thank the staff and patients at the Eric Williams Medical Sciences Complex Emergency Department.

Contributors LDF, SG, ROH and PT conceived the study. LD executed the study including data collection, analysis and management. SG, ROH and PT supervised LD (doctoral student) and provided advice on the study design, analysis and interpretation of results. SH acted as a local supervisor for LD during the data collection period at the case study site. LD drafted the article and all authors contributed to the revision of the article. LD takes responsibility for the paper as a whole.

Funding The authors have not declared a specific grant for this research from any funding agency in the public, commercial or not-for-profit sectors.

Competing interests None declared.

Patient consent for publication Not required.

Ethics approval The University of the West Indies Campus Ethics Committee (CEC014/09/16) and the hospital site granted ethical approval.

Provenance and peer review Not commissioned; externally peer reviewed. 
Data availability statement No data are available. The data in this study are in the form of transcripts of observations and conversations which are confidential and not available for data sharing.

Supplemental material This content has been supplied by the author(s). It has not been vetted by BMJ Publishing Group Limited (BMJ) and may not have been peer-reviewed. Any opinions or recommendations discussed are solely those of the author(s) and are not endorsed by BMJ. BMJ disclaims all liability and responsibility arising from any reliance placed on the content. Where the content includes any translated material, BMJ does not warrant the accuracy and reliability of the translations (including but not limited to local regulations, clinical guidelines, terminology, drug names and drug dosages), and is not responsible for any error and/or omissions arising from translation and adaptation or otherwise.

Open access This is an open access article distributed in accordance with the Creative Commons Attribution Non Commercial (CC BY-NC 4.0) license, which permits others to distribute, remix, adapt, build upon this work non-commercially, and license their derivative works on different terms, provided the original work is properly cited, appropriate credit is given, any changes made indicated, and the use is non-commercial. See: http://creativecommons.org/licenses/by-nc/4.0/.

\section{ORCID iDs}

Loren De Freitas http://orcid.org/0000-0002-8431-5311

Steve Goodacre http://orcid.org/0000-0003-0803-8444

\section{REFERENCES}

1 Haraden C, Resar R. Patient flow in hospitals: understanding and controlling it better. Front Health Serv Manage 2004;20:3-15.

2 NHS Institute for Innovation and Improvement. Quality and service improvement tools. UK: NHS Improving Quality, 2006-2013.

3 Damelio R. Thinking about work. In: Damelio R, ed. The basics of process mapping. New York: CRC Press, 2007: 21-30.

4 De Freitas L, Goodacre S, O'Hara R, et al. Interventions to improve emergency department patient flow: an umbrella review. EMJ 2018;35:626-37.

5 Asaro PV, Lewis LM, Boxerman SB. The impact of input and output factors on emergency department throughput. Acad Emerg Med 2007; 14:235-42.

6 Hodkinson PW, Wallis LA. Emergency medicine in the developing world: a delphi study. Acad Emerg Med 2010;17:765-74.

7 Razzak J, Beecroft B, Brown J, et al. Emergency care research as a global health priority: key scientific opportunities and challenges. BMJ Glob Health 2019;4:e001486.

8 World Health Organisation. Emergency and trauma care. Emergency care systems for universal health coverage: ensuring timely care for the acutely ill and injured, 2019. Available: https://apps.who.int/gb/ ebwha/pdf_files/WHA72/A72_31-en.pdf

9 Pan American Health Organisation. Health in the Americas. Country report: Trinidad and Tobago. USA: Pan American Health Organisation, 2017. Available: https://www.paho.org/salud-en-lasamericas $-2017 / ? \mathrm{p}=4311$

10 Nielsen AL, Hilwig H, Kissoon N, et al. Discrete event simulation as a tool in optimization of a professional complex adaptive system. Stud Health Technol Inform 2008;136:247-52.

11 De Freitas L. Exploring the factors that influence patient flow in an emergency department [thesis]. Sheffield: University of Sheffield, 2019.

12 Johnson P, Duberley J. Pragmatism and critical realism: transcending descartes' either/or. In: Johnson P, Duberley J, eds. Understanding management research: an introduction to epistemology. London: SAGE publications, 2000: 149-76.

13 Yin R. Case study research: design and methods. 5th ed. UK: Sage Publications, 2014

14 Patton MQ. Strategic themes in qualitative inquiry. In: Patton $M Q$, ed. Qualitative research and evaluation methods. 3rd ed. California: SAGE Publications, 2002: 37-73.

15 Fletcher AJ. Applying critical realism in qualitative research: methodology meets method. Int J Soc Res Methodol 2017;20:181-94.
16 Phillips J, Simmonds L. Use of process mapping in service improvement. Nurs Times 2013;109:24-6.

17 Canadian Association of Emergency Physicians. Implementation guidelines. triage and acuity scale definitions. Ottawa: Canadian association of emergency physicians, 2016. http://caep.ca/ resources/ctas/implementation-guidelines

18 Slowther A, Boynton P, Shaw S. Research governance: ethical issues. J R Soc Med 2006;99:65-72.

19 Fry M, Curtis K, Considine J, et al. Using observation to collect data in emergency research. Australas Emerg Nurs J 2017;20:25-30.

20 Braun V, Clarke V. Using thematic analysis in psychology. Qual Res Psychol 2006;3:77-101.

21 Spencer L, Ritchie J, O'Connor W, et al. Analysis in practice. In: Ritchie J, Lewis J, Nicholls C, et al, eds. Qualitative research practice. A guide for social science students and researchers. California: SAGE Publications, 2014: 296-345.

22 Phillips J, Simmonds L. Using Fishbone analysis to investigate problems. Nurs Times 2013;109:18-20.

23 Tang C, Chen Y, Lee S. Non-Clinical work counts: facilitating patient outflow in an emergency department. Behav Inf Technol 2015;34:585-97.

24 Van Vaerenbergh C. Using mixed methods to identify factors influencing patient flow. Health Serv Manage Res 2009;22:170-5.

25 Bashkin O, Caspi S, Haligoa R, et al. Organizational factors affecting length of stay in the emergency department: initial observational study. Isr J Health Policy Res 2015;4:38.

26 Nugus P, Holdgate A, Fry M, et al. Work pressure and patient flow management in the emergency department: findings from an ethnographic study. Acad Emerg Med 2011b;18:1045-52.

27 Burström L, Starrin B, Engström M-L, et al. Waiting management at the emergency department - a grounded theory study. BMC Health Serv Res 2013;13:95.

28 Lyons M, Brown R, Wears R. Factors that affect the flow of patients through triage. Emerg Med J 2007;24:78-85.

29 Aaronson E, Mort E, Soghoian S. Mapping the process of emergency care at a teaching hospital in Ghana. Healthc 2017;5:214-20.

30 Suriyawongpaisal P, Kamlungkuea T, Chiawchantanakit N, et al. Relevance of using length of stay as a key indicator to monitor emergency department performance: case study from a rural hospital in Thailand. Emerg Med Australas 2019;31:646-53.

31 Boiko O, Edwards M, Zschaler S, et al. Interprofessional barriers in patient flow management: an interview study of the views of emergency department staff involved in patient admissions. $J$ Interprof Care 2020;6:1-9.

32 Zibrowski E, Shepherd L, Booth R, et al. A qualitative study of the theory behind the chairs: balancing lean-accelerated patient flow with the need for privacy and confidentiality in an emergency medicine setting. JMIR Hum Factors 2019;6:e11714.

33 Gharaveis A, Kirk Hamilton D, Shepley M, et al. Design suggestions for greater teamwork, communication and security in hospital emergency departments. Indoor and Built Environment 2019;28:1126-39.

34 Department of Health. Health building note 15-01: accident and emergency departments. Planning and design guidance, 2013. Available: https://assets.publishing.service.gov.uk/government/ uploads/system/uploads/attachment_data/file/206267/15_01final3 v3.pdf

35 Al Owad A, Samaranayake P, Karim A, et al. An integrated lean methodology for improving patient flow in an emergency department - case study of a Saudi Arabian Hospital. Production Planning \& Control 2018;29:1058-81.

36 Effects of nurse migration on healthcare improvement. $B M$ 2018;361:k2014.

37 UK Royal College of Nursing. Safe and effective staffing: nursing against the odds. UK: Royal College of Nursing, 2017.

38 Sheer B, Wong FKY. The development of advanced nursing practice globally. J Nurs Scholarsh 2008;40:204-11.

39 Duvald I. Exploring reasons for the weekend effect in a hospital emergency department: an information processing perspective. $J$ Org Design 2019;8:1. 